\title{
Commentary
}

\section{Behavioral Couples Therapy for Substance Use Disorders}

\author{
Keith Klostermann, PhD ${ }^{*}$; Theresa Mignone, PhD $^{2}$ \\ 'Medaille College, 18 Agassiz Circle, Buffalo, NY I 42 I 4, USA \\ ${ }^{2}$ Enlightened Therapies of Western New York, Williamsville, NY I 422I, USA

\section{${ }^{*}$ Corresponding author} \\ Keith Klostermann, PhD \\ Assistant Professor, Department of Counseling \& Clinical Psychology, Medaille College, I8 Agassiz Circle, Buffalo, NY I42 I4, USA; Tel. (7I6) 880-2559; \\ E-mail: kck35@Medaille.edu
}

\section{Article Information}

Received: December 10 ${ }^{\text {th }}, 2018$; Revised: December 26 ${ }^{\text {th }}, 2018$; Accepted: January $5^{\text {th }}, 2019$; Published: January $7^{\text {th }}, 2019$

\section{Cite this article}

Klostermann K, Mignone T. Behavioral couples therapy for substance use disorders. Soc Behav Res Pract Open J. 20I9; 3(I): 25-27. doi: I0. I7I40/SBRPOJ-3-I I3

\section{ABSTRACT}

The results of numerous studies over the past four decades have consistently revealed the effectiveness of couple and family-based approaches for drug and alcohol abuse. Behavioral couples therapy (BCT) is a conjoint approach which has been consistently shown to produce fewer substance-related issues, greater abstinence, and improved dyadic functioning compared to individual-based treatments for married and cohabitating couples. The purpose of the present review is to (a) provide the theoretical rationale for the use of couple's therapy for substance-abusing patients and (b) describe theoretical and practical underpinnings of Behavioral couples therapy for substance use disorders (BCT-SUD) along with key components of this intervention.

\section{Keywords}

Couples therapy; Disorders; Treatment; BCT.

\section{Abbreviations}

BCT: Behavioral Couples Therapy; SUD: Substance Use Disorder; G-BCT: Group BCT; S-BCT: Standard BCT.

\section{BEHAVIORAL COUPLES THERAPY FOR SUBSTANCE USE DISORDERS}

$\mathrm{I}$ is now widely accepted among scholars and clinicians that families play an important part in the development and maintenance of substance misuse problems. In fact, greater numbers of providers at a variety of levels of care (e.g., outpatient, in-patient) have begun incorporating non substance-abusing family members into treatment planning to help support the substance abusers attempts at sobriety. The results of numerous studies have revealed the effectiveness of couple and family-based approaches for drug and alcohol abuse. Behavioral couples therapy (BCT) is a conjoint approach which has been consistently shown to produce fewer substance-related issues, greater abstinence, and improved dyadic functioning compared to individual-based treatments for married and cohabitating couples. ${ }^{1}$ This finding has also been supported by the results of several meta-analyses, which found medium effect sizes favoring the use of family and/or couples therapy relative to other forms of treatment. ${ }^{1}$
When taken as a whole, these findings seem to support the idea that partner-involved treatments are the most broadly efficacious in treating substance use disorders. There is not only substantial empirical support for the use of couple-based treatments in terms of improvements in primary targeted outcomes (e.g., substance use, relationship and family adjustment), but also in other areas that are of clear public health significance (e.g., intimate partner violence, cost-benefit, cost-effectiveness).

Behavioral couples therapy for substance use disorders (BCT-SUD) is a theoretically-based, manualized, and empirically supported treatment based on social learning theory, which suggests that substance abusing couples engage in reciprocal interactional patterns characterized by punishment rather than mutual positive reinforcement of relationship benefitting behaviors., ${ }^{2,3}$ The purpose of this commentary is to provide a rationale for the use of couples therapy for treating substance use disorders and describe the main components of this intervention. 


\section{BEHAVIORAL COUPLES THERAPY FOR SUBSTANCE ABUSE}

The link between substance use and relationship distress may be best conceptualized as "reciprocal causality". Alcoholism and drug abuse by one partner often contributes to relationship problems (e.g., high-levels of relationship dissatisfaction, instability, conflict, sexual dissatisfaction, psychological distress, partner violence). Simultaneously, relationship problems are strongly linked to substance use and may serve as a trigger for lapse o (or relapse) among clients-both during and after treatment. ${ }^{5-7}$ Thus, substance use and relationship problems seem to reinforce one another in reciprocal patterns which can be difficult to disengage from.

BCT-SUD has two primary objectives that are based on the areas discussed above: (a) eliminate (or reduce) substance use and (b) alter dyadic and family interaction patterns to create healthier relationships, which can support the client's recovery efforts and is more conducive to long-term recovery. Simply stated, the goal of BCT is to strengthen the relationship by teaching the partners skills for re-introducing caring behaviors, improving communication and conflict resolution skills, and engaging in continuing recovery activities as a way to promote long-term stability and relapse prevention. The therapist enlists the partner's support in the client's recovery and encourages the partners to engage in healthier behaviors as a unit (improved communication, conflict resolution, etc.).

\section{PRIMARY BEHAVIORAL COUPLES THERAPY TREATMENT ELEMENTS -}

As discussed by Geel, ${ }^{8}$ historically BCT-SUD was divided into various treatment phases each concurrently addressing substance use and relationship dysfunction. In the first phase, the engagement phase, the therapist determines whether the couple as a unit is a viable candidate for BCT by assessing the couple's motivation, commitment, and goals by inquiring about each of these areas in initial sessions to help the therapist and each partner understand the current state of the relationship. It's not uncommon for partners to have discrepant levels of motivation. In such situations, partners are encouraged to follow-through with BCT activities (in-session and in between) and to consider using the first three sessions as a chance to determine if BCT is a good fit and if relationship satisfaction is improving or not. Following this is the first "active" phase of treatment, during which the therapist assists the substance-abusing patient with managing the substance. Subsequently, treatment moves on to improving the couple's relationship via analysis of and skill-building within the relationship (e.g., re-introduction of caring behaviors [Catch your partner doing something nice, shared rewarding activities, caring days], communication skills training [verbal, non-verbal communication, use of "I" statements], conflict resolution skills [Time-out, solve problem-solving method], which is then followed by the ongoing recovery stage. More recently, there has been a shift to recognizing that these stages are not mutually exclusive, and that the treatment and joining process likely begins with first client contact.
The primary method for addressing problematic substance use involves the use of a recovery contract (RC) in which the couple, with the help of the therapist, identifies positive and supportive activities, which are conducive to both short- and longterm recovery and may include self-help activities, church groups, and other positive, abstinence-related activities that the client (and partner) may find helpful. The trust discussion is one of the central activities of the RC and involves the partners engaging in a daily trust discussion in which the client states his or her intent to not use drugs or alcohol and the partner thanking the client for his or her efforts and offering positive support as needed. For example, a simple trust discussion script might include the following statements:

Client: I've been sober for the past 24 hours and plan to be sober for the next 24 hours. Thanks for all your help and support.

Partner: Thanks for being sober for the past 24 hours and plans to be sober for the next 24 hours; let me know how I can help and support.

The trust discussion is meant to be short and positive and serve as a way to begin rebuilding trust between partners. Although clients may initially believe the trust discussion to be exclusively about their drinking, it also can be very powerful for partners who have endured a great deal of lying about substance use and worry about future use, despite not explicitly talking about it. As partners become more comfortable with this daily ritual, they are encouraged to personalize the language to make the content more meaningful for them. Urine tests are also often used to provide objective evidence to support the client's claims. In addition, the couple is asked to agree to four promises during their participation in BCT which include: 1) agreement to focus on the present instead of the past, 2) participate in home practice between sessions, 3) engage in role-plays and other in-session activities, and 4) not engage in "angry touching" (partner violence). These four areas have been identified as trouble spots for many couples so agreeing to these promises at the beginning of BCT can helpful in keeping the couple on track. Clients are also asked each week about urges and urges to use and how he or she managed these feelings. Self-help and other positive supportive activities are also encouraged as part of the RC.

Given the consequences of long-term substance abuse on relationships, many partners have stopped engaging in caring behaviors toward one another and may not be communicating at all, especially with emotionally-charged topics. In an effort to address these concerns, partners are encouraged to re-introduce caring behaviors back into the relationship through activities such as caring days and shared rewarding activities. Partners are also taught basic communication skills to begin to communicate more efficiently and effectively with one another. Relatedly, these skills are then used as a foundation for managing and discussing conflict and how to ensure each partner feels heard and understood by the other.

Given that group therapy is the most frequently used treatment modality in substance abuse treatment, ${ }^{1}$ compared a 
rolling admission Group BCT (G-BCT) format the Standard BCT (S-BCT) approach. Unfortunately, results of this study indicated that in the last 6-9 months of the 12-month follow-up period, G-BCT produced significantly worse substance and relationship outcomes as opposed to S-BCT. More specifically, there was a decrease in days abstinent over time, as well as lower relationship satisfaction over time. It is important to note that in some instances, the aforementioned outcomes were comparable upon immediate completion of S-BCT and G-BCT, but that differences arose once more time elapsed. ${ }^{1}$ These results are not exactly ideal, but this type of research concerning G-BCT is still in its beginning phases.

\section{CONCLUSION}

Couples therapy as an intervention for alcoholism and drug abuse has made substantial strides since its inception in the 1970s. From a clinical vantage point, a fundamental goal for BCT-SUD researchers and clinicians continues to be the transfer of this well-established treatment technology to substance abuse treatment providers such that BCT will be more available to drug- and alcohol-abusing couples who are likely to benefit from participating in the program. Group formats of BCT could potentially aid in dissemination, but research in this area is still in infancy. ${ }^{1}$ McGovern et $\mathrm{al}^{9}$ concluded that in order for treatments to be successfully disseminated, investigators must clearly demonstrate the relevance of the treatment to clinicians and staff, even if empirical support is already established. ${ }^{9}$ Other factors to consider include degree of difficulty in implementation, how closely (or not) the treatment is aligned with the therapist's preferred theoretical orientation or agency counseling approach, cost of providing treatment, and whether or not the treatment fills a perceived area of need for the clinic. Along these lines, development of web-based BCT-SUD training materials has the potential to reach a much wider audience and be a more cost-effective option. Each of these areas may serve as a potential barrier to successful dissemination of the treatment.

Moreover, substance abuse treatment research is beginning to shift away from a "one-size-fits-all" perspective and move toward adaptive interventions which call for different dosages of treatment to be employed strategically with patients across time dependent on severity of presenting issues and concerns. Given the heterogeneity in patient characteristics and response to treatment, future studies are needed to develop a tailored BCT intervention based on treatment algorithms that dictate treatment modifications triggered by the patient's initial response and changes in symptom severity. ${ }^{10}$

\section{REFERENCES}

1. O'Farrell TJ, Schumm JA, Dunlap LJ, Murphy MM, Muchowski P. A randomized clinical trial of group versus standard behavioral couples therapy plus individually based treatment for patients with alcohol dependence. J Consult Clin Psychol. 2016; 84(6): $497-$ 510. doi: 10.1037/ccp0000089

2. Byrne MC, Carr A, Clark M. The efficacy of behavioral couples therapy and emotionally focused therapy for couple distress. Contemporary Family Therapy. 2004; 26(4): 361-387. doi: 10.1007/ s10591-004-0642-9

3. Jacobson NS, Margolin G. Marital Therapy: Strategies Based on Social Learning and Behavior Exchange Principles. Abingdon-on-Thames, UK: Routledge. 1979.

4. Wesley KC. The use of behavioural couple therapy and couple-based interventions in the treatment of substance use disorders. Addiction Research \& Theory. 2016; 24(2): 89-92. doi: $10.3109 / 16066359.2015 .1022160$

5. Epstein EE, McCrady, BS. Behavioral couples treatment of alcohol and drug use disorders: Current status and innovations. Clin Psychol Rev. 1998; 18(6): 689-711. doi: 10.1016/S02727358(98)00025-7

6. Lemke S, Brennan PL, Schutte KK, Moos RH. Upward pressures on drinking: Exposure and reactivity in adulthood. J Stud Alcohol Drugs. 2007; 68(3): 437-445. doi: 10.15288/jsad.2007.68.437

7. Maisto SA, O’Farrell TJ, Connors GJ, McKay JR, Pelcovitz M. Alcoholics' attributions of factors affecting their relapse to drinking and reasons for terminating relapse events. Addict Behav. 1988; 13(1): 79-82. doi: 10.1016/0306-4603(88)90028-7

8. Geel AD. An introduction to behavioral couples therapy. Clinical Psychology Forum. 2016; 278: 22-25.

9. McGovern MP, Fox TS, Xie, H, Drake RE. A survey of clinical practices and readiness to adopt evidence-based practices: Dissemination research in an addiction treatment system. J Subst Abuse Treat. 2004; 26(4): 305-312. doi: 10.1016/j.jsat.2004.03.003

10. Klostermann K, Kelley ML, Mignone T, Pusateri L, Wills K. Behavioral couples therapy for substance abuse: Where do we go from here?. Subst Use Misuse. 2011; 46(12): 1502-1509. doi: $10.3109 / 10826084.2011 .576447$ 